\title{
Decontamination Effects of Ozone Generated in an Atmospheric-pressure Air Plasma on Packaged Fruits
}

\author{
Se Youn Moon* and A-Young Moon \\ Department of Quantum System Engineering, Chonbuk National University, \\ Jeonju 54896, Republic of Korea
}

Received February 22, 2019; revised March 20, 2019; accepted March 27, 2019

\begin{abstract}
Atmospheric-pressure plasma has recently been intensively studied for agricultural product treatment because of its strong decontamination effect and its abundant active agents such as atomic oxygen, ozone, and ultra-violet radiation. However, detailed mechanistic studies of plasma and agricultural products have yet to be conducted. In this study, a dielectric barrier air-discharge plasma was used to treat fruit in packages, and its decontamination mechanism was studied through plasma characterization, microbiological analysis, and food-quality check. By heating the gas introduced for plasma generation and filling packages, we found that the plasma-treated gases enabled better storage conditions for fruits without significant quality degradation. In addition, the control of ozone concentration was revealed to be one of the main decontamination factors.
\end{abstract}

Keywords: Atmospheric-pressure air plasma, Plasma decontamination, Fruit storage, Ozone control, Plasma characterization

\section{Introduction}

Recently, non-equilibrium atmospheric-pressure plasmas have attracted growing attention in food science, agricultural industry, and biological and clinical applications, because of the high concentration of sterilizing agents, such as reactive oxygen species (ROS), reactive nitrogen species (RNS), charged particles, and ultra-violet (UV) radiation [1-11]. In addition, the atmospheric-pressure plasmas having low gas temperature, similar to room temperature, reduce the harmful thermal-damage to targets even in direct contact with plasma [5-8]. For this reason, the interests in plasma treatment of foods and agricultural products have considerably increased, and plasma treatment seems the method of choice for the improvement of food shelf life. Indeed, agricultural products are easily influenced by spoilage microorganisms after harvest, such as viruses, fungi, yeast, and bacteria which can lead to deterioration in quality during dis-

${ }^{*}$ Corresponding author

E-mail: symoon@jbnu.ac.kr tribution or storage [1-7,12-15]. In addition, faster quality deterioration and shorter shelf life by higher respiration rate and/or higher water activity of fresh products results in tremendous economic losses $[1,16,17]$. For example, in the US, the economic loss by the spoilage of agricultural products before being transferred to customers is estimated about 33 billion dollars per year [16]. Therefore, many methods, such as pesticide, insecticide, modified atmosphere packaging (MAP), electrolyzed water washing, and plasma treatment have been developed and evaluated to reduce the loss of fresh products through microorganism disinfection [14-18]. Among them, plasma treatment appears as an emerging technology that avoids the environmental hazards met in conventional chemical methods, the accumulation of solid wastes in MAP, and difficulties in using irradiation [17-19]. In addition, the atmospheric-pressure plasmas are preferred in fresh fruit treatment, because they allow continuous process in open air, and do not accelerate undesirable phase transitions, comparing to the use of conventional low-pressure plasmas produced in vacuum chambers [19,20]. However, the lack of knowl- 
edge concerning the decontamination mechanism of atmospheric-pressure plasmas on agricultural products limits the diverse use of plasmas, and also raises concerns about their adverse effects $[19,20]$.

Therefore, in this work, a dielectric barrier discharge (DBD) plasma at atmospheric pressure was developed to flow plasma treated air gas into the package, while avoiding direct contact between plasma and fruits. Also, we evaluated the effect of plasma treated air gas on the properties and shelf life of strawberries and cherry tomatoes. Strawberry is a popular fruit worldwide due to its special flavor and nutrients, but remains one of the most delicate and perishable fruits, because it is easily deteriorated by physical injuries, water loss, and fungi [21,22]. On the other hand, tomatoes are available all year, and are also consumed worldwide, due to their abundant vitamins [23,24]. However, since both strawberries and tomatoes have a relatively short postharvest life, due to easy deterioration during packing and transportation, the development of ripening control, such as atmospheric-pressure plasma treatment, is economically important to reduce the large annual loss by spoilage [21-24].

\section{Materials and methods}

Figure 1 shows a schematic illustration of the experimental setup. The atmospheric-pressure DBD plasma source for air gas treatment was composed of a cylindrical copper rod (diameter: $3 \mathrm{~mm}$, length: $110 \mathrm{~mm}$ ) encircled by a dielectric quartz tube (diameter: $6 \mathrm{~mm}$, length: $120 \mathrm{~mm}$ ). A grounded copper coil wound the dielectric tube. The copper rod was connected to a high-voltage amplifier source (APPP-020 EESYS) to control output voltage $\left(\mathrm{V}_{\text {out }}\right)$ by adjusting input dc voltage $\left(\mathrm{V}_{\text {in }}\right)$. Plasma treatment was conducted at atmospheric pressure in open air. With or without ozone filter (12218 Ozone Solution), the plasma treated gas having different ozone concentration was collected into a Tedlar ${ }^{\circledR}$ gas sampling bag $(\mathrm{C}$ type Dongbang Hightech) having a length of $16 \mathrm{~cm}$ and a width of $27.5 \mathrm{~cm}$. In order to control the temperature of introducing air gas, the gas feeding line was wound by heat band connected to a heater (TC200 MTOPS), and the gas temperature was monitored by a thermometer as seen in Fig. 1. The discharge voltage and current were measured using two

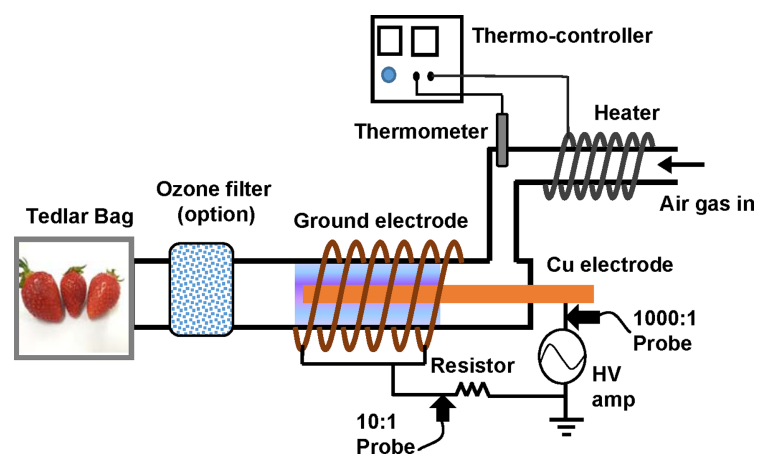

Figure 1. (Color online) A schematic of the experimental atmospheric-pressure dielectric barrier discharge system set-up. An ozone filter and gas heater winding on the gas injecting tube were used to control ozone concentration in plasma.

electric probes (1,000:1 voltage probe, PPE 20KV LeCroy and 10:1 voltage probe, PP 009 LeCroy) with an oscilloscope (WaveSurfer44MXs-B LeCroy). A spectrometer (SCT-320 Princeton Instruments) equipped with a charge-coupled device (CCD, PIXIS400B Princeton Instrument) was used to measure plasma emission spectra.

Fresh strawberries and tomatoes purchased from a local market (Jeonju, Republic of Korea) were stored at $4{ }^{\circ} \mathrm{C}$ for $1 \mathrm{~h}$ before the experiments. To confirm the effect of plasma treatment gas on fruits, the fruits were stored in packages filled with untreated air and/ or plasma treated air gas at room temperature. Three sample bags having 3-5 fruit were prepared for the same experimental conditions. After passing a certain time in packages, a part of pulp and skin (3-5 g) was collected and transferred to a sterile conical tube for homogenizing using a vortex mixer (KMC-1300V Vision Scientific) with 1:10 distilled water for $1 \mathrm{~min}$. In microbiological analysis, an average value with its standard deviation were used by five repetition for each condition. Distilled water was used for decimal serial dilution and $1 \mathrm{~mL}$ of each diluted solution was inoculated on yeast and mold count plate Petrifilm ${ }^{\mathrm{TM}}$ (3M Microbiology, USA). The plates were incubated for $72 \mathrm{~h}$ at $25^{\circ} \mathrm{C}$. The number of fungi in colony forming units (CFUs) was manually counted, and represented as Log CFU/g.

\section{Results and discussion}

Figure 2(a) shows a typical voltage and current waveform at $30 \mathrm{kHz}$ frequency with $120 \mathrm{~V}_{\text {in }}$. The air 
(a)

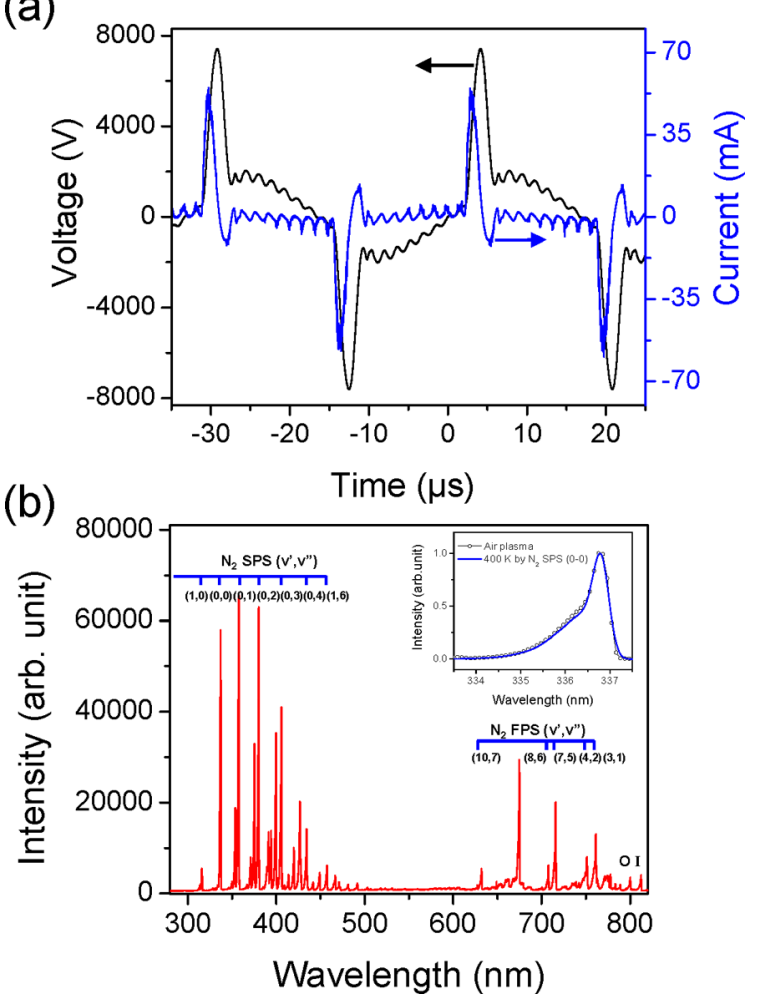

Figure 2. (Color online) (a) Waveforms of discharge voltage (black line) and current (blue line), and (b) the air plasma emission spectrum at $120 \mathrm{~V}_{\text {in }}$. The main spectra are emitted by the excited nitrogen molecules, such as the second positive system (SPS), and first positive system (FPS). The insert in (b) shows that the experimentally obtained $\mathrm{N}_{2}$ SPS (0-0) is well matched with the synthetic spectrum having $400 \mathrm{~K}$ of rotational temperature.

plasma was generated with $15 \mathrm{~L} / \mathrm{min}$ air flow rate, and showed $15 \mathrm{kV}$ peak-to-peak discharge voltage and $110 \mathrm{~mA}$ peak-to-peak discharge current. Figure 2(a) shows that the electrical waveform is similar to a semi-pulsed shape with $2.88 \mathrm{~ms}$ pulse width at fullwidth at half-maximum of the voltage profile. Due to air gas injection, most components of the plasma emission spectra were nitrogen molecular bands, such as the second positive system (SPS, 300-500 nm, $\mathrm{C}^{3} \mathrm{P}_{\mathrm{u}^{-}}$ $\mathrm{B}^{3} \mathrm{P}_{\mathrm{g}}$ ) and first positive system (FPS, 700-850 nm, $\left.\mathrm{B}^{3} \mathrm{P}_{\mathrm{g}}-\mathrm{A}^{3} \mathrm{~S}_{\mathrm{u}}\right)$ as seen in Fig. 2(b). Atomic oxygen lines (777 and $844 \mathrm{~nm}$ ) known as active species that contribute to the inactivation of spores were also observed, due to the oxygen composition of air [25]. The plasma gas temperature $\left(\mathrm{T}_{\mathrm{g}}\right)$ was evaluated by analyzing the nitrogen molecular emission spectrum. High $\mathrm{T}_{\mathrm{g}}$ is often related to the production of reactive plasma species, and also causes thermal damage to fresh agricultural products, such as changes in color, (a)

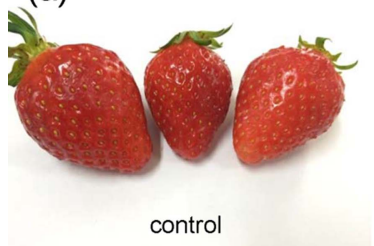

(c)

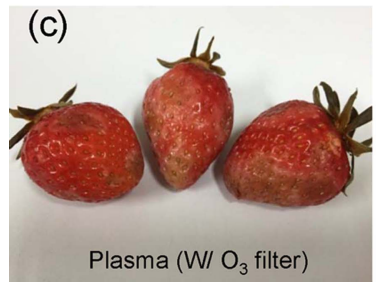

(b)

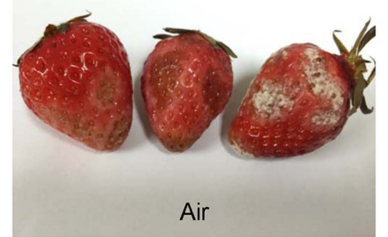

(d)

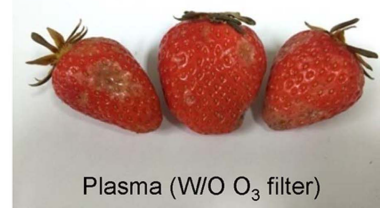

Figure 3. (Color online) (a) Photos of initial strawberries as a control, and strawberries stored in (b) air, (c) plasma treated air without ozone, and (d) plasma treated air with ozone for 7 days.

flavor, and surface texture [26,27]. The $\mathrm{T}_{\mathrm{g}}$ in plasma was determined by a well-known synthetic spectrum method using the diatomic molecular spectra of nitrogen [28]. At atmospheric pressure, the rotational temperature $\left(\mathrm{T}_{\text {rot }}\right)$ measured by the synthetic spectrum method generally shows a similar value to $\mathrm{T}_{\mathrm{g}}$, due to frequent collision between neutral molecules [28,29]. $\mathrm{T}_{\mathrm{g}}$ was calculated by comparing the theoretical synthetic spectrum with the measured molecular rotational emission spectrum for a given $\mathrm{T}_{\text {rot }}$ is shown in the insert of Fig. 2(b). The measured plasma gas temperatures for all experiments were found to be under $400 \mathrm{~K}$, which value is negligible thermal effect of plasma on the fruits.

In a previous work, we showed that the plasma treated air gas improved the shelf life of grape, strawberry and cherry tomato, based on a quantitative fungi analysis performed by yeast and mold count plate Petrifilm ${ }^{\mathrm{TM}}$ [30]. In particular, the fungi colony density of the plasma treated air case rapidly decreased for $12 \mathrm{~h}$, and then gradually increased, because of ozone formation by plasma and decomposition in the package. Ozone formation in atmospheric-pressure DBDs has been well reported [5,31], but the mechanistic study for fruit decontamination of ozone was not well proved. Therefore, in this work, we studied the quantitative effects of ozone generated and controlled by plasmas.

Figure 3 describes the status of strawberries before storing (a) and the rotting statuses of strawberries stored in (b) air, (c) plasma treated air without ozone, 
(a)

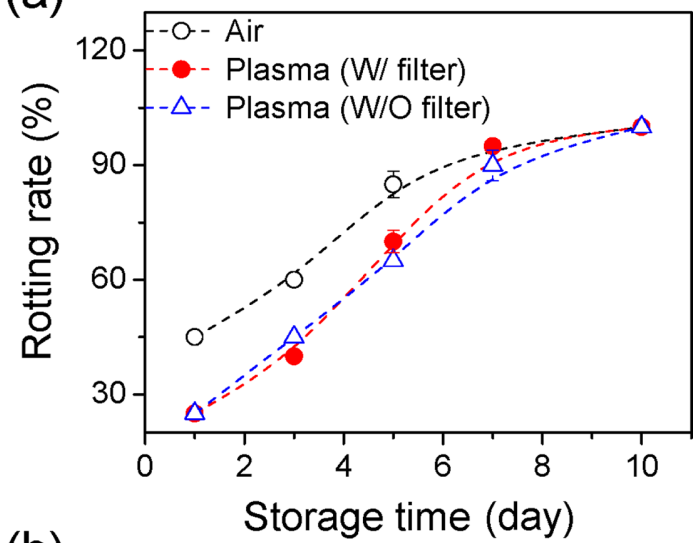

(b)

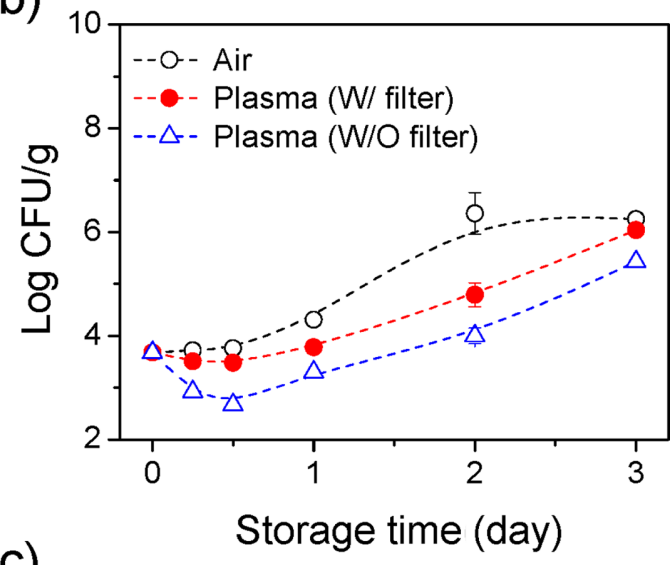

(c)

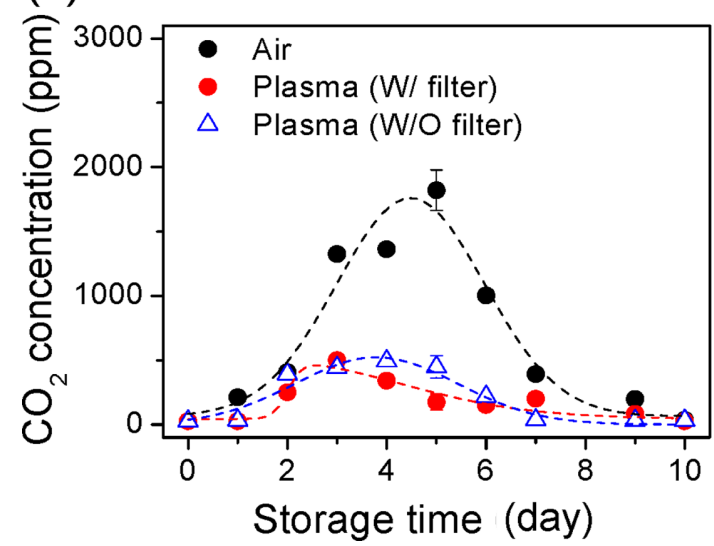

Figure 4. (Color online) (a) Rotting rates, (b) survival curve of fungi, and (c) $\mathrm{CO}_{2}$ concentration of strawberries stored in air (- $\bigcirc-)$, plasma treated air without ozone (-O-), and plasma treated air with ozone $(-\triangle-)$. All data were analyzed by taking strawberries from each package for each day.

and (d) plasma treated air with ozone for 7 days. By inserting an ozone filter before filling the package (Fig. 1), the ozone produced by the plasma source was completely removed. After filtration, the concentration of ozone, measured by two kinds of ozone sensors (UV-106M Ozone Solution and A-22 ECO SENSORS) with unit of parts per million (ppm), was decreased from 342 to $0 \mathrm{ppm}$. Compared to the storage condition in air, both plasma treated air cases showed better rotting statuses. It is worth noting that the plasma treated air with ozone seems to lead to the best storage conditions among them. Figures 4(a) and 4(b) show that the rotting rate and microbiological analysis. The rotting rate was analyzed using 20 strawberries for each condition. Until 7 days, both plasma treated cases showed lower rotting rate, but merged into $100 \%$ at 10 days. Hence, those microbiological analysis results proved that the plasma treated air gas can delay the decontamination of fresh fruits. Figures 4(a) and 4(b) indicate that the ozone produced by the plasma is very effective in improving the shelf life of strawberries, but is not the only active agent in the plasma. The oxygen atoms and/or reactive nitrogen would also be active agents to increase the microbial degradation. Figure 4(c) shows the $\mathrm{CO}_{2}$ concentration, allowing the respiration rate of strawberry stored at different times to be detected. At the same time, strawberries were stored in packages filled by air, plasma treated air with ozone, and without ozone. After every one-day storage in the package, the strawberries were carefully moved into a gas jar (Vernier VE0810, $2 \mathrm{~L}$ volume) having a $\mathrm{CO}_{2}-\mathrm{O}_{2}$ sensor (Vernier VE8710, VE0620). The jar was sealed to make airtight conditions, and the strawberries were stored at $25{ }^{\circ} \mathrm{C}$ for $10 \mathrm{~min}$ for sensing the respiration rate. Since the damage or stress induced by the treatment methods could show a higher respiration rate, the measurement of the respiration rate of strawberries stored in plasma treated air is likely to be important [32,33]. In Fig. 4(c), however, the respiration rates of the plasma treated air cases were found to be lower than that of the control (stored in air), which is most likely due to the decreased microbial count [33]. In particular, in elevated $\mathrm{O}_{2}$ atmospheres, a lower respiration rate has been reported [34]. On the other hand, in this work, since the strawberry stored in plasma treated air was transferred to a gas jar, the respiration rate would not be influenced by the atmosphere condition. Therefore, the plasma treated air storage (with and without ozone) could promise microbial degradation without significant stress in strawberries.

These results show that the ozone generated by plasma is important to increase the fruit shelf life without quality degradation; however, this may not be the only effect of the ozone. This lack of knowledge 
(a)

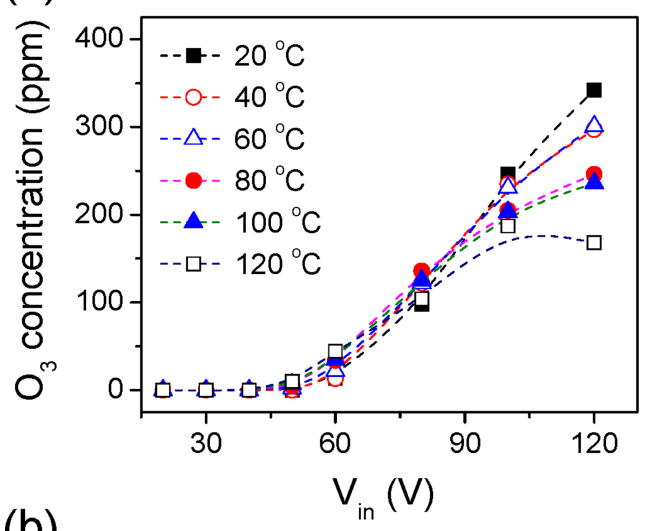

(b)

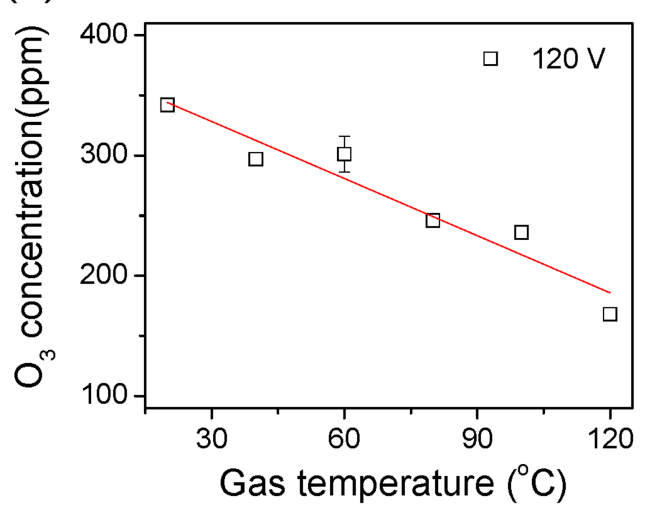

(c)

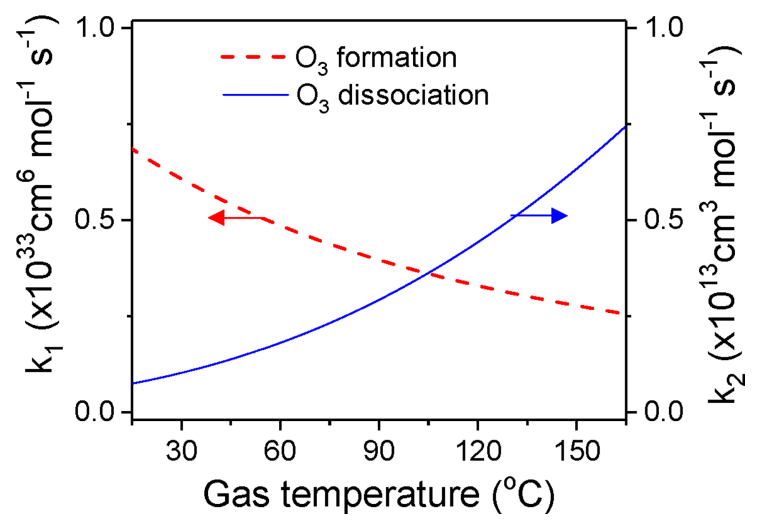

Figure 5. (Color online) (a) Ozone concentrations for various introducing gas temperatures with respect to input voltages. (b) When the input voltage is $120 \mathrm{~V}_{\mathrm{in}}$, the ozone concentration is linearly decreased from $342 \mathrm{ppm}$ at $20^{\circ} \mathrm{C}$ to 168 ppm at $120^{\circ} \mathrm{C}$. (c) The calculated reaction rate constants for different gas temperatures from 30 to $150{ }^{\circ} \mathrm{C}$ based on ozone formation reaction (red dashed line) and ozone decomposition reaction (blue solid line).

concerning the decontamination mechanisms by atmospheric-pressure plasmas on agricultural products limits the diverse uses of plasmas, and also raises concerns about adverse effects. Indeed, ozone sometimes changed the product qualities, such as color degradation, and generated a disgusting odor [19,22]. In addition, recognition of the health risks of high levels of ozone, such as breathing problems, triggering of asthma, reduced lung function and lung diseases has led to tough regulations and standards for ambient air concentration. Therefore, in this work, we also discussed the control of ozone generation by plasma and its effect on the fruits.

To control the ozone generation in atmospheric-pressure plasmas, the gas temperature of introduced air was varied from 20 to $120{ }^{\circ} \mathrm{C}$ by adding heating components as seen in Fig. 1. Figure 5(a) shows the variation of ozone concentration with respect to input voltages and gas temperatures. Above $60 \mathrm{~V}_{\text {in }}$, the ozone concentration was abruptly increased, due to the onset of plasma. For higher input voltages, the reduction of ozone by higher gas temperature was more effective. For example, at $120 \mathrm{~V}_{\text {in }}$, the ozone concentration was linearly decreased from $342 \mathrm{ppm}$ at $20{ }^{\circ} \mathrm{C}$ to $168 \mathrm{ppm}$ at $120{ }^{\circ} \mathrm{C}$ as seen in Fig. 5(b). The contribution of the introducing gas temperature is based on the competition of ozone formation and decomposition. There are many reaction pathways to form or decompose ozone [35]. For example, the following reactions, known as Chapman reactions, are the most important neutral chemical reactions for ozone formation (R1) and decomposition (R2)[35]:

$$
\begin{aligned}
\mathrm{O} & +\mathrm{O}_{2}+\mathrm{M}{ }^{\circledR} \mathrm{O}_{3}+\mathrm{M} \mathrm{k}_{1} \\
& =\left(6.0^{\prime} 10^{-34}\right)(\mathrm{T} / 300)^{-2.8}[\mathrm{M}] \mathrm{cm}^{6} \mathrm{~mol}^{-1} \mathrm{~s}^{-1} \\
\mathrm{O} & +\mathrm{O}_{3}{ }^{\circledR} \mathrm{O}_{2}+\mathrm{O}_{2} \mathrm{k}_{2} \\
& =\left(8.0^{\prime} 10^{-12}\right) \exp (-2060 / \mathrm{T}) \mathrm{cm}^{3} \mathrm{~mol}^{-1} \mathrm{~s}^{-1}
\end{aligned}
$$

where, $\mathrm{M}$ and $[\mathrm{M}]$ are a third body, such as $\mathrm{O}_{2}$ and its density in $\mathrm{cm}^{-3}$, respectively. $\mathrm{T}$ is the gas temperature in Kelvin, and $\mathrm{k}_{1}$ and $\mathrm{k}_{2}$ are the reaction rate constants for ozone formation and decomposition, respectively. Figure 5(c) shows the calculated reaction rate constants for different air gas temperatures from 30 to $150{ }^{\circ} \mathrm{C}$ based on $\mathrm{R} 1$ and $\mathrm{R} 2$. By increasing the gas temperature, the heated gas suppresses the ozone generation and increases the ozone dissociation, which is in good agreement with the experimental results shown in Figs. 5(a) and 5(b).

In these conditions, we also discussed the effect of introducing gas heating on the shelf life of cherry tomatoes. Figure 6(a) shows the microbiological anal- 

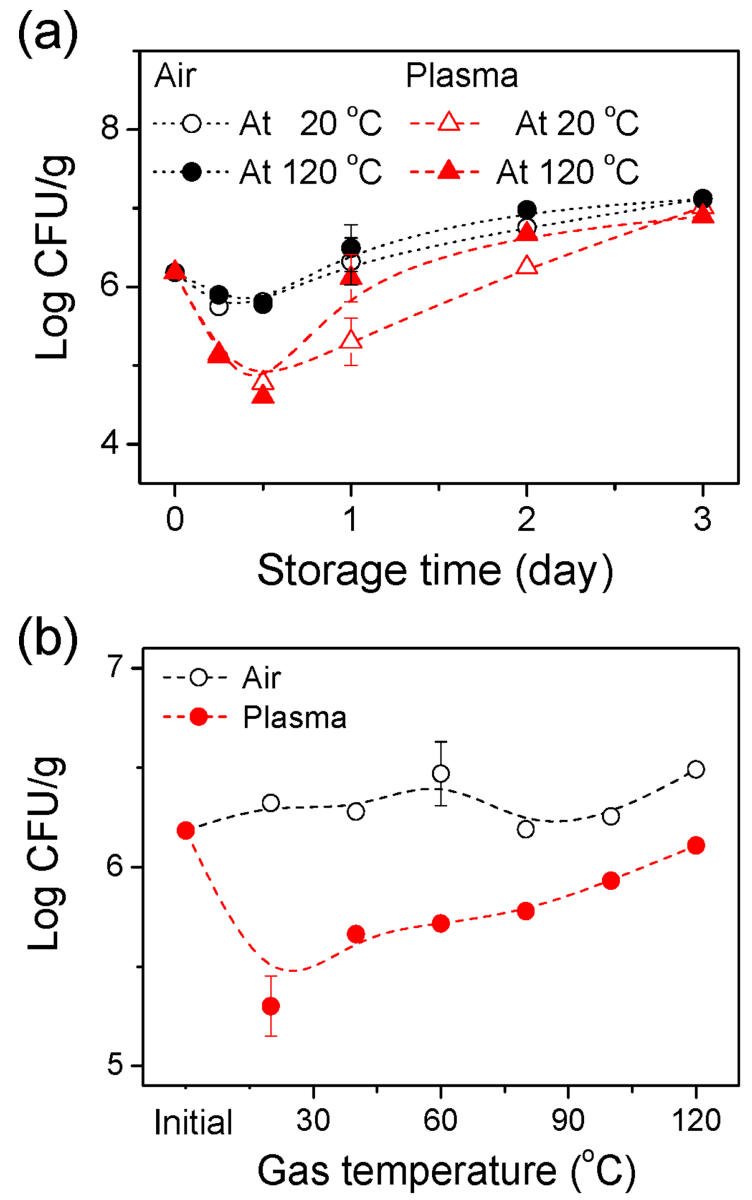

(c)

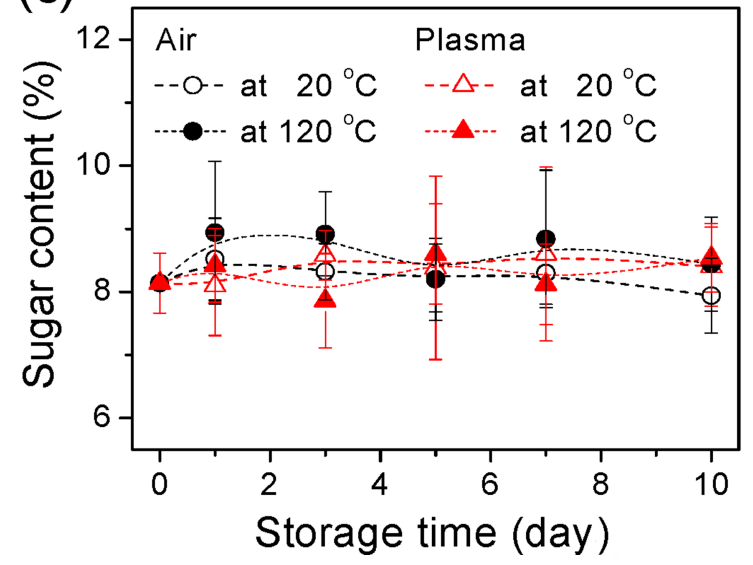

Figure 6. (Color online) (a) Quantitative analysis of fungi of cherry tomatoes stored in air at $20^{\circ} \mathrm{C}\left(-\mathrm{O}_{-}\right)$, air at $120^{\circ} \mathrm{C}\left(-\mathrm{O}_{-}\right)$, plasma treated air at $20^{\circ} \mathrm{C}(-\triangle-)$, and plasma treated air at $120^{\circ} \mathrm{C}(-\Delta-)$. (b) Gas temperature effects on the fungi numbers of cherry tomatoes stored in air (-O-) and plasma treated air (-) for 1 day. (c) Storing conditions, such as air and plasma treated air with different gas temperatures, show non-significant changes in sugar contents.

ysis results for different temperatures of 20 and $120^{\circ} \mathrm{C}$, with and without plasma treated gas. In the result, it was shown that the gas heating effect in the case of untreated air was negligible. On the other hand, the plasma treated cases showed some discrepancy after 1 day of storage. To see the decontamination effects of gas heating in detail, we counted fungi colony densities of cherry tomatoes stored for 1 day in the packages filled with untreated and plasma treated air for various gas temperatures. As shown in Fig. 6(b), the untreated air cases do not show any meaningful dependence on the gas temperature. However, the plasma treated cases clearly showed a strong dependence of the fungi decontamination on the gas temperature, which means the ozone concentration controlled by gas heating is likely to be one of the main mechanisms of decontamination in this work. Even for the lowest ozone concentration case, i.e. the $120{ }^{\circ} \mathrm{C}$ condition, the colony density (6.1 Log CFU/g) was still lower than that of untreated air case $(6.5$ Log CFU/g), which is promising for the control of ozone concentration with storage improvement. The sugar contents expressed by percentage of degree Brix using a refractometer (SCM-1000 HM DIGITAL) was also investigated for various gas temperature conditions, and Fig. 6(c) shows that the results did not show any remarkable effect of gas temperature for either air or plasma cases.

\section{Summary}

Quantitative effects of ozone generated by air plasma on fresh fruits stored in a closed package were studied through plasma characterization, microbiological analysis, and food quality check. The atmospheric-pressure air plasma was generated in a coaxial DBD system by 30 $\mathrm{kHz}$ low frequency power. In plasma emission spectra, $\mathrm{N}_{2}^{+}, \mathrm{N}_{2}$ (SPS), $\mathrm{N}_{2}$ (FPS), and $\mathrm{O}$ were mainly observed, and a plenty of ozone in the plasma was generated. An ozone filter and gas heating system were used to control the concentration of ozone produced in the plasma to see the quantitative effects of ozone on the fruit decontamination in packages. By filtering ozone and changing the ozone concentration by tuning the introducing gas temperature, we found the ozone concentration was the main decontaminating factor in this work, and was controllable for safety issue without a significant loss of shelf life improvement. The results show that atmospheric-pressure air plasma can improve the shelf life of fresh fruits through fungi decontamination in a storing package, while having little effect on fruit quality changes. 


\section{Acknowledgments}

This work was supported by the Basic Science Research Program through the National Research Foundation of Korea (NRF) funded by the Ministry of Education (NRF-017R1D1A1B03029401).

\section{References}

[1] M. Ito, T. Ohta, and M. Hori, J. Korean Phys. Soc. 60, 937 (2012).

[2] W. J. Kowalski, W. P. Bahnfleth, and T. S. Whittam, Ozone Sci. Eng. 20, 205 (1998).

[3] J. H. Choi, I. Han, H. K. Baik, M. H. Lee, D. W. Han, J. C. Park, I. S. Lee, and K. M. Song, J. Electrostat. 64, 17 (2006).

[4] A. Fridman, Plasma Chemistry, Cambridge University Press, New York, 2008.

[5] G. Fridman, G Friedman, A. Gutsol, A. B. Shekhter, V. N. Vasilets, and A. Fridman, Plasma Process Polym. 5, 503 (2008).

[6] B. Kim, H. Yun, S. Jung, Y. Jung, H. Jung, W. Choe, and C. Jo, Food Microbiol. 28, 9 (2011).

[7] S. Tappi, A. Berardinelli, L. Ragni, and M. D. Rosa, A. Guarnieri, and A. Rocculi, Innov. Food Sci. Emerg. 21, 114 (2014).

[8] M. Laroussi, Plasma Process Polym. 2, 391 (2005).

[9] S. J. Kim and T. H. Chung, Sci. Rep. 6, 20332 (2016).

[10] E. Stoffels, A. J. Flikweert, W. W. Stoffels, and G. M. W. Kroesen, Plasma Sources Sci Technol. 11, 383 (2002).

[11] H. J. Kim, D. D. Jayasena, H. I. Yong, A. U. Alahakoon, S. Park, J. Y. Park, W. Choe, and C. Jo, J. Food Sci Technol. 52, 8410 (2015).

[12] S. Jung, H. J. Kim, S. Park, H. I. Yong, J. H. Choe, H. Jeon, W. Choe, and C. Jo, Meat Sci. 108, 132 (2015).

[13] D. P. Park, Curr. Appl. Phy. 13, s19 (2013).

[14] J. Hayma, The Storage of Tropical Agricultural Products, $4^{\text {th }}$ ed., Agromisa Foundation, Wageningen, Netherlands, 2003.

[15] J. I. Pitt and A. D. Hocking, Fungi and Food Spoilage, 2nd ed., Aspen Publishers, Gaithersburg, 1999.
[16] D. Pimentel, R. Zuniga, and D. Morrison, Ecol. Econ. 52, 273 (2005).

[17] D. Raheem, J. Food Agric. 25, 177 (2012).

[18] J. W. Jeong, J. H. Kim, K. H. Kwon, and K. J. Park, Korean J. Food. Preserv. 3, 316 (2006).

[19] B. Ramos, F. A. Miller, T. R. S. Brandão, P. Teixeira, and C. L. M. Silva, Innov. Food Sci. Emerg. 20, 1 (2013).

[20] O. Schlüter, J. Ehlbeck, C. Hertel, M. Habermeyer, A. Roth, K.-H. Engel, T. Holzhauser, D. Knorr, and G. Eisenbrand, Mol. Nurt. Food Res. 57, 920 (2013).

[21] D. Dong, C. Zhao, W. Zheng, W. Wang, X, Zhao, and L. Jiao, Sci. Rep. 3, 2585 (2013).

[22] A. Perez, C. Sanz, J. J. Rios, R. Olias, and J. M. Olias, J. Agric. Food Chem. 47, 1652 (1999).

[23] A. M. Opiyo and T. J. Ying, Int. J. Food. Sci. Technol. 40, 665 (2005).

[24] C. Fagundes, K. Moraes, M. B. Perez-Gago, L. Palou, M. Maraschin, and A. R. Monteiro, Postharvest Biol. Technol. 109, 73 (2015).

[25] M. Moisan, J. Barbeau, M. C. Crevier, J. Pelletier, N. Philip, and B. Saoudi, Pure Appl. Chem. 74, 349 (2002).

[26] S. Y. Moon, D. B. Kim, B. Gweon, W. Choe, H. P. Song, and C. Jo, Thin Solid Films 517, 4272 (2009).

[27] M. Vleugels, G. Shama, X. T. Deng, E. Creenacre, T. Broucklehurst, and M. G. Kong, IEEE Trans. Plasma Sci. 33, 824 (2006).

[28] S. Y. Moon and W. Choe, Spectrochim. Acta Part B 58, 249 (2003).

[29] S. Pellerin, J. M. Cormier, F. Richard, K. Musiol, and J. Chapelle, J. Phys. D. Appl. Phys. 29, 726 (1996).

[30] A. Y. Moon, S. Noh, S. Y. Moon, and S. J. You, Curr. Appl. Phys. 16, 440 (2016).

[31] U. Kogelschartz, B. Eliasson, and W. Egli, J. Phys. IV 7, 47 (1997).

[32] D. Rico, A. D. Martin-Diana, J. M. Barat, and C. BarryRyan, Trends Food Sci. Technol. 18, 373 (2007).

[33] N. N Misra, T, Moiseev, S, Patil, S. K. Pankj, P. Bourke, J. P. Mosnier, K. M. Keener, and P. J. Cullen, Food Bioprocess Technol. 7, 3045 (2014).

[34] A. L. Wszelaki and E. J. Mitcham, Postharvest Biol. Technol. 20, 125 (2000).

[35] K. H. Becker, M. Schmidt, A. A. Viggiano, R. Dressler, and S. Williams, Non-equilibrium air plasmas at atmospheric pressure, IOP Publishing, Bristol and Philadelphia, 2005, Ch.4. 